CODA | PATIENT PORTRAITS

a series by Seema Marwaha

\section{Rob Lackie}

Cite as: CMAJ 2021 August 9;193:E1224. doi: $10.1503 / \mathrm{cmaj} .211281$

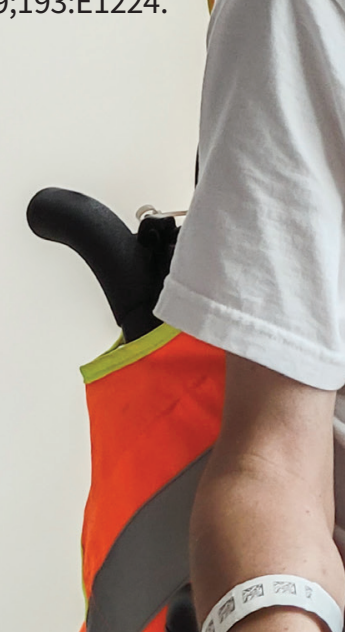

am Inuit. I was born in Happy Valley, Newfoundland and Labrador, the most southern community in our ancestral territory. My mom is a residential school survivor. When I was born, the Canadian government deemed her unfit to be a mother (which was not true), and I was placed into foster care. I didn't meet my mom until I was in my mid-30s. I didn't know I had any siblings. Now I know I have a younger sister. I was in my fourth foster home when I was adopted by a non-Indigenous family in Ontario. This is what consecutive generations of assimilation looks like. The Government of Canada has torn many Indigenous families apart this way.

I studied business administration and worked for big banks before moving to the education sector. I wanted to make a bigger impact on people's lives and think about more than just being a part of the bottom line for big business. My focus has been to help Indigenous youth access education from elementary to postsecondary. It's really challenging for so many of them to progress in their education without adequate resources. I won an award from Aboriginal Affairs for this work in 2011.

I was diagnosed with severe rheumatoid arthritis in 1989 and I've had 15 surgeries, mostly in relation to this. My last major surgery was in 2018, which has led me to require a powered wheelchair.

When in a hospital, I am rarely asked if I'm Indigenous (many assume I am from the Philippines). When I have had a bad hospital experience, I wonder if my race is the main factor.
Recently, I was admitted to a stroke unit because I had difficulty moving the left side of my body. I'm deaf in my right ear and have only partial hearing in my left. When I would press the call button, I could not hear when the call was being answered. Eventually, the staff member answering the calls got upset with me for calling so many times and hung up on me when we finally connected. It is harmful to discourage people to ask for help when they are sick.

My pain medication was stopped abruptly by a doctor in training without any discussion with me, my admitting doctor or even my family physician. I was in such severe pain from the sudden stop that I couldn't get out of bed. Just because I'm Indigenous does not mean I will get addicted to pain medications. Any culture or race is at a similar risk of addiction.

I posted about my pain on social media and some prominent community advocates stepped in. It's unfortunate that Indigenous people need to have advocates involved to make our health care better. We don't know if this is just the way the system works or if we are being labelled, prejudged and racialized by the system. Either way, it's deeply unfair and the system needs to be fixed now.

Content licence: This is an Open Access article distributed in accordance with the terms of the Creative Commons Attribution (CC BY-NCND 4.0) licence, which permits use, distribution and reproduction in any medium, provided that the original publication is properly cited, the use is noncommercial (i.e., research or educational use), and no modifications or adaptations are made. See: https://creativecommons. org/licenses/by-nc-nd/4.0/ 